This is an Accepted Manuscript (post print version) of an article published by Springer in Archives of Sexual Behavior.

\title{
A Prototype Willingness Approach to the Relation between Geo-Social Dating Apps and Willingness to Sext with Dating App Matches \\ Lara Schreurs (MSc) $)^{1-2}$, Sindy Sumter $(\mathrm{PhD})^{3}$ and Laura Vandenbosch $(\mathrm{PhD})^{1}$
}

Affiliations: ${ }^{1}$ School for Mass Communication Research, Faculty of Social Sciences, KU Leuven, Leuven Belgium; ${ }^{2}$ Research Foundation Flanders (FWO-Vlaanderen), Belgium; ${ }^{3}$ Amsterdam School of Communication Research, University of Amsterdam, the Netherlands

Email addresses: lara.schreurs@kuleuven.be; s.r.sumter@uva.nl;

laura.vandenbosch@kuleuven.be;

Please cite as follows: Schreurs, L., Sumter, S. R., \& Vandenbosch, L. (2020). A Prototype Willingness Approach to the Relation between Geo-Social Dating Apps and Willingness to Sext with Dating App Matches. Archives of Sexual Behavior. doi:10.1007/s10508-020$01671-5$

Correspondence concerning this article should be addressed to Laura Vandenbosch, School for Mass Communication Research, KU Leuven, Parkstraat 45, B-3000 Leuven, Belgium, laura.vandenbosch@kuleuven.be 


\begin{abstract}
Despite voiced concerns about sexual online risk behaviors related to mobile dating, little is known about the relation between mobile dating and sexting. The current crosssectional study $(N=286)$ examined the relations between the use of geo-social dating apps and emerging adults' willingness to sext with a dating app match. By drawing on the prototype willingness model, both a reasoned path and a social reaction path are proposed to explain this link. As for the reasoned path, a structural equation model showed that more frequent dating app usage positively related to norm beliefs about peers' sexting behaviors with unknown dating app matches (i.e., descriptive norms), norm beliefs about peers' approval of sexting with matches (i.e., subjective norms), and negatively related to perceptions of danger to sext with matches (i.e., risk attitude). In turn, descriptive norms positively and risk attitudes negatively associated to individuals' own willingness to sext with someone they had met through a dating app. As for the social reaction path, it was found that more frequent dating app usage positively related to emerging adults' favorable evaluations of a prototype person who sexts with unknown dating app matches (i.e., prototype perceptions). The analyses further revealed that such prototype perceptions positively linked with emerging adults' own willingness to sext with a match. These results were similar among women and men and help explain why individuals may be willing to engage in sexting behavior with unknown others.
\end{abstract}

Keywords: dating apps; sexting; emerging adulthood; prototype willingness model 


\section{INTRODUCTION}

For many emerging adults, the introduction of dating apps changed and potentially facilitated their interpersonal communication with potential romantic partners (Sumter, Vandenbosch, \& Ligtenberg, 2017). Dating app communication differs from (1) offline communication as important social contextual cues are lacking (Hallam, Walrave, \& De Backer, 2018) and from (2) communication through website-based dating services as potential partners are quickly selected based on spatial proximity (Lutz \& Ranzini, 2017). These unique features of dating apps may facilitate sexual unrestricted communication (e.g., sexting between individuals who are sexually/romantically interested in each other) (Helsper \& Whitty, 2010).

Sexting can be defined as the sending of semi- to highly sexually explicit images through the Internet (Mitchell, Finkelhor, Jones, \& Wolak, 2012). Some researchers have questioned whether sexting has become normative as empirical findings suggest that this practice is quite prevalent among today's emerging adults (Mori et al., 2020). This prevalence is surprising as sexting does not merely have positive consequences (e.g., Wiederhold, 2015); in some contexts, sexting has been linked to various emotional and physical risks (e.g., Benotsch, Snipes, Martin, \& Bull, 2013; Dake, Price, Mariarz, \& Ward, 2012). One of the most salient sexting risks is the forwarding of compromising images by the receiver without consent. A recent meta-analysis showed that $15 \%$ of emerging adults engage in this practice and thus forward sexts non-consensually (Mori et al., 2020), which may cause serious harm to the sender's reputation (Van Ouytsel, Walrave, Ponnet, \& Heirman, 2015). This unwanted distribution of personal images is believed to be higher when sending sexts to a stranger (Baumgartner, Valkenburg, \& Peter, 2010).

As dating apps are designed to facilitate sexual communication with people one does not yet know, they may enhance the likelihood that their users engage in this more risky form 
of sexting. Empirical research supporting this assumption is still missing. Therefore, a central aim of the current cross-sectional study among Dutch emerging adults was to explore whether frequent geo-social dating app usage positively relates to emerging adults' willingness to sext (i.e., sending sexy images of oneself) with a dating app match.

Furthermore, the literature on risk behavior, and in particular the prototype willingness model (PWM) (Gerrard, Gibbons, Stock, Lune, \& Cleveland, 2005), suggests indirect links may also occur between geo-social dating app usage and the willingness to sext. Therefore, a second aim of the study was to explore the relations between geo-social dating app use and sexting willingness with a dating app match as modelled by the PWM.

\section{The Affordances of Dating Apps}

Online dating has opened up the possibility to connect to an infinite number of potential partners (Finkel, Eastwick, Karney, Reis, \& Sprecher, 2012). For a long time, online dating seemed to carry some social stigma; people tended to think negatively about such sites and saw members as "desperate" (Anderson, 2005; Donn \& Sherman, 2002). This stigma appears to have lessened following the inception of dating apps (Ranzini \& Lutz, 2017). Geosocial dating apps possess several unique affordances which distinguish them from the more traditional dating web services. Firstly, geo-social dating apps enable the selection of partners in the user's spatial proximity (Sawyer, Smith, \& Benotsch, 2018). Additionally, apps like Tinder strongly rely on a quick selection of partners based on visual self-presentations through images and limited textual information (Lutz \& Ranzini, 2017). Moreover, as geosocial dating apps are installed on mobile devices, they can be used anywhere anytime (Ranzini \& Lutz, 2017; Sawyer et al., 2018).

Apparently, this unique dating app context has promoted online dating (Ward, 2016). Moreover, the less sexually restricted interactions dating apps trigger seem to fit nicely within emerging adults' intense explorations of sexuality and romance. In line with these 
assumptions, we have witnessed a strong uptake in the use of dating apps, in particular among emerging adults. For example, $22 \%$ of U.S. 18-24 year olds reported using mobile dating apps in 2015, compared to 5\% in 2013 (Smith \& Anderson, 2016).

\section{Dating Apps, Sexting, and Emerging Adults}

Sexual and romantic explorations increase during emerging adulthood (18-25 years; Arnett, 2000; Willoughby \& Caroll, 2010). Emerging adulthood is characterized by an increased need for independence, a heightened focus on the self, and a more intense exploration of one's identity (Arnett, 2000; Morgan, 2013). It is against this backdrop that emerging adults develop their sexual self, exploring and identifying sexual and romantic preferences and gaining experience in different kinds of relationships (Fincham \& Cui, 2011). For most, these explorations are in the service of starting a stable, committed relationship, i.e., a prominent developmental goal (Netting \& Burnett, 2004). Because of this goal, sexual and romantic explorations are more prevalent in emerging adulthood than in any other period of the life-course (Claxton \& van Dulmen, 2013).

Dating apps provide emerging adults with a unique digital space to satisfy their relational needs and facilitate their sexual and romantic explorations (Sumter \& Vandenbosch, 2018). Emerging adults' unprecedented and increasing level of engagement with dating apps suggests these apps are becoming the dominant tool to initiate sexual/romantic contacts with novel partners among this age group.

When getting to know a partner (on- and offline), it is important that both partners feel sexually attracted to each other to obtain desired sexual/romantic goals (Hallam et al., 2018; Poulsen, Holman, Busby, \& Caroll, 2013). Sexting may be one of the strategies emerging adults apply to evoke sexual interest and attraction among a potential partner on a dating app (Burkett, 2015). Current research estimates that $38 \%$ of emerging adults send sexts, $42 \%$ receive sexts and 48\% engage in reciprocal sexting (for an overview, see Mori et al., 2020). 
Research showed that such sexting practices among emerging adults could trigger positive consequences such as sexual satisfaction (Wiederhold, 2015). Yet, at the same time, sexting among emerging adults has been associated with a wide range of risk behaviors, such as unprotected sex and substance use (Benotsch et al., 2013; Dake et al., 2012). Moreover, new technologies (i.e., dating apps) are claimed to facilitate such sexual online communication (e.g., sexting; Helsper \& Whitty, 2010). Against this backdrop, we hypothesized the following:

H1: More frequent geo-social dating app usage is positively related to emerging adults' willingness to sext with a dating app match.

The current study specifically focused on behavioral willingness. As sexting with an unknown partner is considered a sexual online risk behavior (Baumgartner et al., 2010; Van Ouytsel et al., 2015), emerging adults may not always deliberately engage in this behavior, but could be willing to do so when the situation lends itself to it (van Oosten \& Vandenbosch, 2017). It has been argued that behavioral willingness is an important predictor of future engagement in the behavior (Boot, Peter, \& van Oosten, 2016; Gibbons, Gerrard, Blanton, \& Russell, 1998). Therefore, behavioral willingness is deemed a key construct in the context of sexting with unknown dating app matches and was the main outcome variable in the current study.

\section{The Prototype Willingness Model}

To better understand emerging adults' willingness to sext with matches, the current study draws on the PWM (Gerrard et al., 2005). Two pathways are proposed to explain risk behavior in the PWM.

First, the PWM builds on norm theory and how one's environment can shape one's behavior (Gibbons et al., 1998). The model reasons that individuals engage in risk behavior through a reasoned path in which environmental factors (i.e., media use) affect (1) attitudes 
about the favorability of the behavior (risk attitudes), (2) norm beliefs regarding the number of important others who engage in the risk behavior (descriptive norms), and (3) norm beliefs regarding the extent to which important others approve of the risk behavior (subjective norms) (Gerrard et al., 2005). In turn, these attitudes and norms affect users' willingness to perform the risk behavior.

With regards to sexting, this means that emerging adults form attitudes towards sexting by analyzing relevant information accessible in their offline and online environment (Bohner \& Dickel, 2011). In turn, these attitudes will guide their behavior (Glasman \& Albarracín, 2006). Moreover, human behavior is fueled by, often incorrect, perceptions of how important others act and think (Berkowitz, 2005). In the case of emerging adults, following the diminishing influence of parents, their peers become important role models (Borsari \& Carey, 2001).

When using dating apps, a user will likely notice that some peers present themselves in a sexual manner, as some users post sexy profile pictures and share sexting images with dating app partners (Albury \& Byron, 2014). The more frequently individuals use these apps, the more likely it will be that they encounter sexual cues. Accordingly, they may increasingly believe that many peers engage in sexting and approve of sexting behavior. Moreover, by seeing peers send sexting images of themselves, engaging in sexting can gradually become a practice that is believed to lead to favorable outcomes (i.e., positive attitudes/norms). Note that actual encounters with sexting images are not necessary for triggering favorable norm/attitudinal beliefs according to the theory. Cues suggesting sexual availability (e.g., sexy selfies as a profile picture) may already socialize a more general sexually permissive orientation that, in turn, will shape someone's norms and attitudinal beliefs (van Oosten, Peter, \& Boot, 2015; van Oosten, Peter, \& Vandenbosch, 2017). 
Empirical social media research seems to support some of this reasoning. For instance, van Oosten et al. (2017) showed that adolescents who were regularly exposed to sexually suggestive photos of peers reported higher levels of descriptive peer norm beliefs on casual sex over time. Subsequently, the favorable descriptive peer norm beliefs related positively to willingness to engage in casual sex. Together, theory and research suggest that increased dating app usage relates positively to a more favorable attitude concerning dangers attached to sexting to a partner met online and subjective/descriptive norm beliefs concerning sexting with dating app matches.

Second, the PWM proposes that the relation between (social) media use and risk behavior can also be explained by a social reaction path that depends on how favorable an individual thinks of a typical actor of the risk behavior (i.e., favorable prototype) (Gerrard et al., 2005). This pathway is believed to trigger behavior in a more spontaneous way and focuses on the likeability of peers who typically engage in the behavior (Gerrard et al., 2005). So far, one study has supported this pathway for social media use and showed that emerging adults who shared more sexy selfies online were more positive about peers who engaged in casual sex. In turn, these so-called favorable prototypes of peers engaging in casual sex positively related to a willingness to engage in casual sex themselves (van Oosten et al., 2017). Favorable prototype perceptions have also been related to adolescents' willingness to send sexting messages (Walrave et al., 2015). Thus, in line with these findings, we expect that emerging adults who use dating apps more often will be more likely to endorse favorable prototypes of app users who sext with matches and, consequently, are more willing to sext with unfamiliar matches themselves.

Drawing on the PWM, a dual pathway model is suggested which may explain the relations between dating app usage and emerging adults' willingness to sext with a match (Fig. 1). Accordingly, the following hypothesis was tested: 
H2: Low risk attitudes, positive descriptive norm beliefs, positive

subjective norm beliefs, and positive prototype perceptions mediate the relation between the frequency of geo-social dating app usage and emerging adults' willingness to sext with a dating app match.

Note that research on the PWM has pointed at the importance of an adapted approach for conceptualizing norms and prototypes among men and women as youth often particularly identify with same-sex prototypes and value norms of their same-sex peers (van Oosten et al., 2017). Therefore, the current study will conceptualize emerging adults' perceptions about prototypes and norms in alignment with their gender (and use gender-specific measures).

\section{The Moderating Role of Gender and Control Variables}

The hypothesized relations in the proposed model may differ according to gender. Engaging in sexting is less accepted for women, though women receive the most pressure to sext (van Oosten \& Vandenbosch, 2017). At the same time, women are also known to be more careful in their interactions with dating app matches compared to men (Griffin, Canevello, \& Mcanulty, 2018). Accordingly, we may expect women would be less likely to increase their willingness when their norms or attitudes change as a result of increased dating app use. Therefore, our third hypothesis is as follows:

H3: The relations between dating app usage and sexting willingness ( $\mathrm{H} 1$ and $\mathrm{H} 2)$ will be moderated by gender. Specifically, these are stronger among men than women.

Furthermore, the literature suggests that age, sexual orientation, and relationship status may affect the relations under scrutiny. Some studies showed, for instance, that sexting occurs less often among older and heterosexual adults (Klettke et al., 2014). Also, dating apps are used less often by heterosexual compared to non-heterosexual emerging adults (Sumter \& Vandenbosch, 2018), and used more often by people who are single compared to those in a 
relationship (Griffin et al., 2018). Therefore, age, relationship status, and sexual orientation were used as control variables.

\section{METHOD}

\section{Participants}

This study reports on data taken from a larger online study (via Qualtrics and approved by the ethical committee of the department of communication science, University of Amsterdam $)^{1}$. The research agency 'PanelClix' recruited a sample of 370 participants with a mean age of 24.60 years $(S D=3.41$; range $18-30$ years), $50.8 \%$ women and $15.7 \%$ not exclusively heterosexual. Considering living situation, $34.9 \%$ of the respondents lived with their parents, $20 \%$ lived alone, $23 \%$ lived together with their partner but without children, 8.9\% shared a house with peers, $11.9 \%$ lived with their partner and one or more children, and $0.5 \%$ lived alone with one or more children. Many respondents were in a committed romantic relationship at the time of the study $(66.2 \%)$ and the majority of the sample identified as being Dutch (92.2\%).

Data were collected through a research agency in order that the study drew on a representative sample of emerging adults in the Netherlands instead of a convenience sample of students, which is often the case when researching emerging adults. Participants were informed about confidentiality measures and given the option to withdraw active consent within a week. Participants could skip questions when feeling uncomfortable or being unfamiliar with dating apps and received $€ 3,50$ as a reward. A total of 128 men and 158 women $(N=286)$ had no missing data (i.e., analytical sample).

\section{Measures}

\footnotetext{
${ }^{1}$ The current study uses data that was part of a larger project that examined geo-social dating app usage among emerging adults. More information about the project can be obtained by sending an email to the first author.
} 
The present study included new measurement instruments related to sexting with unknown dating app matches. An in-depth review of the literature guided the creation of these measures. Specifically, we followed the literature on norms (Ajzen, 2002), the PWM (Gerrard et al., 2005; Gibbons \& Gerrard, 1995), and studies applying the concepts of the PWM to specific topic (e.g., Hukkelberg, \& Dykstra, 2009; van Oosten et al., 2017; Walrave et al., 2015). Next, researchers experienced in sexuality research reviewed and adapted the items. Specific questions and response options can be found in the Appendix.

\section{Control Variables}

Participants indicated their age, sexual orientation (sexually attracted only to boys $=1$, mainly to boys, but also to girls $=2$, equally to boys and girls $=3$, mainly to girls, but also to boys $=4$, only to girls $=5$, or don't want to indicate the answer $=6)^{2}($ Kinsey, Pomeroy, $\&$ Martin, 1948; Peter \& Valkenburg, 2011), and relationship status (1 = committed relationship with partner met through dating app, 2 = committed relationship with partner not met through dating app, $3=$ single $)$. Sexual orientation $(0=$ exclusively heterosexual, $1=$ not exclusively heterosexual $)$ and relationship status $(0=$ single, $1=$ committed relationship) were transformed into dichotomous variables.

\section{Dating App Use}

Participants first indicated whether they had ever used Tinder or another dating app $(0=$ no, $1=$ yes $)$. Next, they indicated whether they were currently using Tinder or another dating app $(0=$ no, $1=$ yes $)$. Current users were first asked which dating app they used most often. Second, they indicated how frequently they had used this app during the last six months. Similarly, prior users were first asked which dating app they used most often. Second, they indicated how frequently they had used this app during the last six months that

\footnotetext{
${ }^{2}$ Concerning the measurement description of sexual orientation, the participants were asked about their attractions to "boys/girls" and not "men/women". This phrasing is commonly accepted in the local translation when young adults are the referent group. Hence, we chose to keep this phrasing in the English translation.
} 
they were still using the app. A 9-point Likert scale was used $(0=$ never to $8=\mathrm{I}$ use(d) the app throughout the day). Higher scores indicate a higher (past) usage frequency.

Descriptive Norms

Based on prior literature on norms (Ajzen, 2002), male/female participants were asked to estimate (respectively) how many of their male/female friends had exchanged sexy photos with a dating app match. The response options ranged from $1=$ nobody to $5=$ all of their friends. Higher scores indicate higher descriptive norm beliefs regarding peers' sexting behavior with dating app matches.

\section{Subjective norms}

Based on prior literature on norms (Ajzen, 2002), male/female participants were asked (respectively) to what extent their male/female friends approve of exchanging sexy photos with a dating app match. The response options ranged from $1=$ fully disapprove to $7=$ fully approve. A variable was created that reported the scores for both males and females. Higher scores indicate higher subjective norm beliefs regarding peers' approval of sexting behavior with dating app matches.

\section{Attitudes}

Based on prior literature on attitudes (Ajzen, 2002), participants indicated how dangerous it was for men/women to exchange sexy photos with a woman/man through a dating app. A variable was created that reflected the scores for both males and females. The response options ranged from $1=$ not dangerous at all to $5=$ very dangerous. Higher scores indicate a stronger risk attitude.

\section{Prototype perceptions}

Drawing on prototypes literature (Gibbons \& Gerrard, 1995), participants imagined a woman/man of their own age who sends sexy photos to a match on a dating app, like Tinder. Next, they indicated how "indicative" they found the following characteristics for this 
woman/man: (1) attractive, (2) interesting, and (3) desired on a 7-point Likert scale (totally not true $=1$ to totally true $=7$ ). Principal components analyses indicated one factor for each gender (men: eigenvalue $=2.77$, explained variance $=92.43 \%, \alpha=.95$, and women: eigenvalue $=2.70$, explained variance $=90.14 \%, \alpha=.96$ ). A variable was created that reflected the scores for both males and females. Higher scores on the mean variable of the items indicate more positive prototype perceptions.

Willingness to sext

Participants imagined meeting someone through a dating app like Tinder with whom they exchanged flirtatious messages, they were told that they found this person highly sexually attractive, and that the attraction was mutual (Gerrard et al., 2005). Next, they estimated the likelihood that they would send this match the following photos: (1) photo of themselves in a sexy pose but without naked body parts, (2) photo of themselves in underwear or swimwear, and (3) nude photo. Answer options ranged from $1=$ highly unlikely to 7 = highly likely. Principal components analyses indicated one factor (men: eigenvalue $=2.58$, explained variance $=86.03 \%, \alpha=.92$ and women: eigenvalue $=2.27$, explained variance $=75.80, \alpha=.84)$. A variable for each item was created that reported the scores for both males and females. Higher scores on the mean variable of the items indicate a higher willingness.

\section{Analytic Strategy}

Descriptive statistics and zero-order correlations were calculated. Next, the hypothesized model (see Fig. 1) was tested using structural equation modelling (AMOS). Control variables were allowed to co-vary with each other and the independent variable dating app use. The four mediating variables (descriptive norms, subjective norms, attitudes, and prototypes) were also allowed to co-vary with each other. The fit was evaluated using CFI ( $\geq .95), R M S E A(\leq .08)$ with $90 \% \mathrm{CI}$, the $\chi^{2} / d f(\leq 5) T L I(\geq .95)$, and SRMR $(\leq .05)$ 
(Byrne, 2010). As variables in sexuality research are often biased (Peter \& Valkenburg, 2011), bias-corrected $95 \%$ bootstrapped $C I$ (1000 samples) were calculated. These intervals also informed us on a potential significant indirect relation between dating apps usage and willingness to sext.

Finally, the fit indices of an unconstrained model were compared with the fit indices of a constrained model (in which the hypothesized relations were constrained to be equal among men and women). The $\chi^{2}$-model comparison test value informed us on potential significant gender differences.

\section{RESULTS}

\section{Descriptive Statistics}

Skewness and kurtosis information indicated a normal distribution of the data (Kline, 2011). The zero-order correlations provided some preliminary evidence of the hypothesized model $(p<.05)$. All descriptive statistics are shown in Table 1.

\section{Hypothesized Model}

The fit of the model was good, $\chi^{2}(38)=74.44, p<.001, C F I=.98, R M S E A=.06$ (95\% CI: .038/.077), TLI $=.95, S R M R=.0491, \chi^{2} / d f=1.96$ (see Fig. 2). Use of dating apps related to descriptive norms, subjective norms, risk attitude, and prototype perceptions. Willingness to sext was related to descriptive norms, risk attitude, and prototype perceptions, but not to subjective norms. Finally, willingness to sext was not directly $(p>.05)$, but indirectly related to dating app use, .081 (bc 95\% bt CI: .051/.122).

\section{Model Comparison Test for Gender}

The model constrain test indicated similar results across gender groups and thus that no significant differences occurred in the hypothesized relations for men and women, $\operatorname{CMIN}(8)=8.35, p=.400$. Also, the differences between the $C F I$ values $(\triangle C F I)$ of both the unconstrained and the constrained models did not exceed .01 . The model fit of the 
unconstrained model was thus not superior to the model constraining the relations between dating app use and willingness to sext to be equal across gender. As no significant gender differences emerged, the path results of the unconstrained model are not presented.

\section{DISCUSSION}

The current study sheds some new light on the mechanisms that explain how dating apps may affect emerging adults' sexuality and dating experiences. Geo-social dating apps are immensely popular among emerging adults (Ward, 2016) yet there has been concern about sexual risk behaviors related to the usage of these apps (Albury \& Byron, 2016; Sawyer et al., 2018). One specific risk may be the sending of self-taken sexually explicit images to an unknown dating app match, as this increases the chance that the sexting images will be forwarded without consent of the sender (Baumgartner et al., 2010).

Even though the PWM was developed prior to the inception of mobile dating apps (Gerrard et al., 2005), the results of the present study demonstrate that the model proves useful in explaining why emerging adults are willing to sext with "unknown" dating app matches. Indirect relations between the frequency of using dating apps and willingness to sext were reported, as modelled by the PWM. In general, our results point at the explanatory value of both the reasoned and the social reaction paths of the PWM (Gerrard et al., 2005).

\section{A Reasoned Path from Dating App Use to Sexting}

As for the reasoned path, the more an emerging adult used dating apps, the less he/she thought it was risky to exchange sexy photos through a dating app. Moreover, these individuals believed that more peers had engaged in sexting with a match and that peers would be more accepting of such sexting behavior, partly supporting H2. We propose two explanations for these relations.

First, the negative relation between dating app usage and risk attitudes may be explained by the presence of sexually explicit communication between dating app matches 
(Albury \& Byron, 2014). Frequent dating app users are more likely to have experienced receiving sexy images from their match (Albury \& Byron, 2014). Receiving sexy images may lead to a process of habituation and the exchange of sexy images may be seen as a normative rather than a dangerous practice (Vandenbosch, 2015). Therefore, users may start to believe that sending sexy images is less risky. This assumption is in line with earlier longitudinal research by van Oosten and Vandenbosch (2017) who showed that exposure to sexy selfies on social media related to a higher willingness to sext among adolescent girls.

Second, the links between dating app usage and descriptive/subjective norms may be explained by a false uniqueness effect, i.e., individuals' underestimation of the extent to which others in the reference group (e.g., the peer group) act in the same way (Bosveld, Koomen, van Der Pligt, \& Plaisier, 1995). Because sexual cues are highly present when interacting with dating app matches (Albury \& Byron, 2014), emerging adults may think that especially others (i.e., the same sex peer group) will be tempted to engage in more sexually explicit and risky practices, such as sexting. Prior research has also reported that such a false uniqueness effect is present in other sexual risk behavior (Stephenson \& Sullivan, 2009). More research is needed to test this explanation.

Surprisingly, descriptive norms were positively associated to willingness to sext whereas subjective norms were not. Norm literature may further explain the different roles that descriptive and subjective norms play in the online dating context. Although individuals generally turn to social norms for behavioral guidance, norm literature suggests that compliance with subjective or descriptive norms is situation dependent (Kenny \& Hastings, 2011).

On the one hand, subjective norms especially guide an individual's behavior when he/she is faced with a situation for which it is evident what the peer group would approve of (i.e., subjective norm) and compliance to that behavior would result in the acceptance by the 
peer group (Pool \& Schwegler, 2007). On the other hand, when people are confronted with an ambiguous situation, i.e., a situation in which it is unclear which behavior is approved by the peer group, they will adjust their behavior to what they belief others are doing rather than thinking (Pool \& Schwegler, 2007). Thus, in ambiguous situations, when individuals are unsure about the dominant subjective norms, they will turn to dominant descriptive norms for behavioral guidance.

With regards to online dating, interpersonal dating interactions often bring along highly ambiguous situations in which individuals are uncertain about the meaning of particular actions of a potential partner (Giordano, Longmore, Manning, 2006). Therefore, descriptive norms may become more influential than subjective norms to guide emerging adults' sexual behavior (i.e., willingness to sext) in (online) dating situations (i.e., while using dating apps).

Furthermore, when emerging adults in the current study felt it was dangerous to sext, they were less willing to sext themselves with an unknown dating app match. Thus, risk attitudes seem to mediate the relation between dating app usage and sexting willingness, supporting H2. This result supports the dominant approach of health campaigns targeting sexting as they often focus on informing individuals about the dangers of sexting (Döring, 2014), which, at least according to our results, associates negatively to one's willingness to sext with an unknown partner. Future research could examine which specific risk concerns translate in behavior change as these campaigns often distinguish between social, legal, educational, career, and abuse risks when they inform youth about sexting (Döring, 2014).

\section{A Social Reaction Path from Dating App Use to Sexting}

Regarding the social reaction path, prototype perceptions seemed to function as an indirect stepping stone in relating dating app usage to willingness to sext in line with $\mathrm{H} 2$. The explanatory relevance of the social reaction path has also been supported in research on, for 
instance, alcohol consumption (Armenta, Hautala, \& Whitbeck, 2015; Litt \& Lewis, 2016) and smoking (Hukkelberg \& Dykstra, 2009). These studies support the idea that prototype perceptions of persons engaging in risk behavior relate to own risk behavior.

The value of prototype perceptions in the context of mobile dating and sexting might also prove a promising direction for future intervention studies. Research has namely suggested that targeting individuals' social reactive responses (i.e., their prototype perceptions) is fruitful in reducing risk behavior that is more impulsive and unplanned (van Lettow, de Vries, Burdorf, Boon, \& Van Empelen, 2015). Specifically, health messages that alter the valence of prototype perceptions can be a useful strategy to reduce such kind of risk behavior among youth. Such an approach has been successfully applied in earlier research, for instance in the context of alcohol consumption (van Lettow et al., 2015) or condom use (Blanton et al., 2001). Additionally, research showed that combining a prototype-based approach with information on descriptive norms on the targeted behavior is even more effective for behavioral change (Crozier \& Taylor, 2019). Thus, it seems that the constructs of the PWM (particularly descriptive norm beliefs and prototype perceptions) are not only appropriate in explaining, but also in preventing risk behavior among emerging adults (Davies, Martin, \& Foxcroft, 2015), future campaigns targeting risky forms of sexting should try and adopt such a prototype-based approach.

\section{The Absent Direct Path between App Use and Sexting Willingness}

The results did not support the hypothesized direct relation between the frequency of using dating apps and emerging adults' willingness to send a sexy image of themselves to a potential partner they had met through a dating app. This finding suggests that the typical features of geo-social dating apps (e.g., absence of typical social contextual cues that hint at the (un)appropriateness of sexually explicit communication) do not seem to promote individuals to directly engage in sexting. 
It is probable that the current study did not find such a direct link as dating app usage was measured rather broadly, instead of looking at the specific content dating app users are exposed to. In this context, prior studies focusing on sexual online self-presentations did not always seem to agree on the direct links between exposure to sexy selfies (which can be encountered in the mobile dating context) and willingness to post/send such images oneself. In this regard, van Oosten and Vandenbosch (2017) found that exposure to sexy selfpresentations of others did not predict the willingness to engage in sexting. The reverse occurred in the study by Baumgartner, Sumter, Peter, and Valkenburg (2015); being more frequently exposed to sexy selfies of peers predicted willingness to post sexual images oneself.

As the current study used a general measure of dating app usage frequency and did not address exposure to sexy self-presentations of others on dating apps in particular, followup studies should include detailed measurement instruments of exposure to sexy selfpresentations of other dating app users or use different research designs (e.g., experiments) to examine whether exposure to such sexual cues on dating apps directly promotes individuals to sext.

\section{The Same Pathways for Men and Women}

Finally, it should be noted that similar relations occurred for men and women; descriptive norms, risk attitudes, and prototype perceptions mediated the link between geosocial dating app usage and sexting willingness whereas subjective norms did not. This finding aligns with the gender similarities hypothesis which states that men and women are psychologically more alike than different (Petersen \& Hyde, 2010) and, therefore, differences within gender are probably larger than differences between genders (Sumter, Valkenburg, \& Peter, 2013). Drawing on this line of literature, our findings suggest that women and men probably respond psychologically in a similar way to norm/attitudinal beliefs and prototype 
perceptions about sexting with an unknown dating app match. It should be noted however that research reported significant gender differences in attitudes, norm beliefs, and prototype perceptions regarding sexting and in their willingness to sext (Walrave et al., 2015). Although the same psychological processes could be at play, men and women might thus still differ in the extent they find sexting with dating app matches dangerous, have positive prototype perceptions of someone who sexts with a match or experience peer pressure to sext with a match. As such, gender remains important within sexting research and additional research is needed to explain these differences between men and women.

\section{Limitations}

Although the current study has been able to shed more light on emerging adults' experiences with dating apps, the study also has some shortcomings. First of all, the present study used a cross-sectional design. Due to this design, no statements about causality can be made. Longitudinal and experimental research is needed. Moreover, cultural differences in sexting practices need to be considered. For instance, a cross-country comparison regarding sexting predictors revealed that gender differences in sexting patterns were more pronounced in traditional countries (Baumgartner, Sumter, Peter, Valkenburg, \& Livingstone, 2014). The present study was conducted in the Netherlands, which is a rather liberal sexual country, which limits the generalization of the results.

Next, as the current study was the first to develop several measures regarding sexting practices with dating app matches within the scope of the PWM, future research is needed to further test the reliability and validity of these newly developed measurement instruments. Also, additional and more detailed measures are needed to gain a more accurate understanding of emerging adults' online sexual behavior with dating app matches. For instance, when it comes to prototype perceptions, it might be interesting to specify whether the photos this person sends are solicited or unsolicited, as individuals might perceive 
someone who sends unsolicited sexting images as less attractive, interesting, and desired. Moreover, it will be interesting to include whether individuals have experience with sexting to someone in general and to dating app matches in particular, as prior experience (which could be positive and/or negative experiences) may influence the relations under scrutiny.

An additional shortcoming is that multiple single-item measures were used which may increase the probability of measurement errors and unknown biases (Gliem \& Gliem, 2003). Yet, some scholars do argue for single-item measures (Gardner, Cummings, Dunham, \& Pierce, 1998; Wanous, Reichers, \& Hudy, 1997). Therefore, future research should compare single-item vs. multiple-item indicators in the dating app context to amplify the evidence for the indirect relations found in the present study.

Finally, the present study focused on behavioral willingness to sext with unknown dating app matches. Even though literature on the PWM (e.g., Gibbons et al.,1998) argues that behavioral willingness is a very likely indicator of engagement in future (sexual) risk behavior, we cannot draw any conclusions on the role of attitudes, norms, and prototype perceptions in emerging adults "actual" sexting behavior with unknown dating app matches. Even though it is highly relevant to consider actual sexting experiences, behavioral willingness may be a more subtle and, therefore, also a more suitable measurement instrument as people are known to underreport their actual sexing behaviors (Van Ouytsel, Walrave, \& Ponnet, 2018). Therefore, future research should move beyond self-reports and think of new ways to explore emerging adults' actual sexting experiences with an unknown partner (Van Ouytsel et al., 2018).

\section{Conclusion}

The present study has extended our knowledge of mobile dating by showing that descriptive norms, risk attitudes, and prototype perceptions functioned as significant mediators in the relation between using dating apps and willingness to sext. These findings 
point out the relevance of both a reasoned path and a social reaction path in explaining emerging adults' willingness to engage in sexual online communication. As such, the PWM seems an appropriate theory to shed more light on the complex associations between geosocial dating apps and willingness to sext.

\section{Compliance with Ethical Standards}

All procedures performed in studies involving human participants were in accordance with the ethical standards of the institutional and/or national research committee and with the 1964 Helsinki declaration and its later amendments or comparable ethical standards.

Informed consent was obtained from all individual participants included in the study. 


\section{APPENDIX}

\section{Measures of Dating App Use}

The questions below are newly developed measures to assess dating app use, all items (Q) and answer categories (A) are provided. ${ }^{3}$

Q1. Do you use Tinder or have you ever used Tinder?

A: Yes, I use Tinder; Yes, I have used Tinder but not anymore; No, I don't use Tinder but I have once downloaded a different dating app; No, I don't use Tinder and I have never downloaded a different dating app

Q2. Have you ever downloaded a dating app which was not Tinder? [question displayed when the respondent indicated 1) Yes, I use Tinder or 2) Yes, I have used Tinder but not any more] A: Yes; No

Q3. Which dating app have you downloaded (multiple answers are possible)? [question displayed when the respondent indicated "Yes" on the question if she/he has ever downloaded a dating app which was not Tinder]

A: Happn; Grindr; Badoo; Blendr; Bumble, Clover; FlirtSmart; GuySpy; Her; Hornet; Hot or Not; Inner Circle; Jack'd; Jaumo; Lexa; Mint; OKCupid; Pepper; Pure; Scruff; Skout; Twoo; A different one, namely ...

Q4. Do you still use one of these apps?

A: Yes; Not any longer

Q5. Which dating app do you use the most often? [question displayed when they indicated at the previous question to be current users]

A: Tinder; Happen; Grindr; Badoo; Blendr; Bumble; Clover; FlirtSmart; GuySpy; Her; Hornet; Hot or Not; Inner Circle; Jack'd; Jaumo; Lexa; Mint; OKCupid; Pepper; Pure; Scruff; Skout; Twoo; A different one, namely ...

\footnotetext{
${ }^{3}$ Note that these scales were developed and questioned in Dutch. These scales were translated in English by the authors.
} 
Q6. Which dating app did you use the most often? [question displayed when they indicated at the previous question to be former users]

A: Tinder; Happen; Grindr; Badoo; Blendr; Bumble; Clover; FlirtSmart; GuySpy; Her; Hornet; Hot or Not; Inner Circle; Jack'd; Jaumo; Lexa; Mint; OKCupid; Pepper; Pure; Scruff; Skout; Twoo; A different one, namely ...

Q7. How often have you used Tinder on average in the past six months? [question displayed for current Tinder users who use Tinder the most often of all dating apps]

A: never; almost never; about once a month; multiple times a month; about once a week; multiple times a week; once a day; multiple times a day; I check Tinder during the whole day Q8. When you think about the last six months of usage, how often did you use Tinder on average? [question displayed for former Tinder users who used Tinder the most often of all dating apps]

A: never; almost never; about once a month; multiple times a month; about once a week; multiple times a week; once a day; multiple times a day; I checked Tinder during the whole day

Q9. How often have you used X [the app they indicated to use the most often which is not Tinder] on average in the past six months? [question displayed for current dating app users] A: never; almost never; about once a month; multiple times a month; about once a week; multiple times a week; once a day; multiple times a day; I check the app during the whole day Q10. How often have you used X [the app they indicated to use the most often which is not Tinder] on average in the past six months? [question displayed for current dating app users] A: never; almost never; about once a month; multiple times a month; about once a week; multiple times a week; once a day; multiple times a day; I checked the app during the whole day

\section{Measures of Descriptive Norms}


Q1. We would like to know more about your male friends' experiences with dating apps such as Tinder. How many of your friends have exchanged sexy photos with a dating app match (e.g., a Tinder match)? [question displayed for men]

A: nobody; less than half; more or less the half; more than half; all of them

Q2. We would like to know more about your female friends' experiences with dating apps such as Tinder. How many of your friends have exchanged sexy photos with a dating app match (e.g., a Tinder match)? [question displayed for women]

A: nobody; less than half; more or less the half; more than half; all of them

\section{Measures of Subjective Norms}

Q1. According to you, what do your male friends think of exchanging sexy photos with someone you have met through a dating app (e.g., a Tinder match)? [question displayed for men]

A: They fully disapprove this; They disapprove this; They disapprove this a little bit; They neither approve, neither disapprove it; They approve this a little bit; They approve this; They fully approve this

Q2. According to you, what do your female friends think of exchanging sexy photos with someone you have met through a dating app (e.g., a Tinder match)? [question displayed for women]

A: They fully disapprove this; They disapprove this; They disapprove this a little bit; They neither approve, neither disapprove it; They approve this a little bit; They approve this; They fully approve this

\section{Measures of Attitudes}

Q1. Dating apps like Tinder: dangerous or not for men? Attention please. These questions are about men of your age who use a dating app. How dangerous is it for a man to exchange sexy 
photos with a woman through a dating app, e.g., with a Tinder match? [question displayed for men]

A: not dangerous at all; not dangerous; neither dangerous, neither not dangerous; dangerous; very dangerous

Q2. Dating apps like Tinder: dangerous or not for women? Attention please. These questions are about women of your age who use a dating app. How dangerous is it for a woman to exchange sexy photos with a man through a dating app, e.g., with a Tinder match? [question displayed for women]

A: not dangerous at all; not dangerous; neither dangerous, neither not dangerous; dangerous; very dangerous

\section{Measures of Prototype Perceptions}

Q1. Imagine a man of your age who sends sexy photos to a match on a dating app, like Tinder. We would like to know which characteristics do you think are indicative for this man. A man who sends sexy photos through a dating app like Tinder is 1) attractive; 2) interesting; 3) desired [question displayed for men]

A: Totally not true; Not true; A little bit not true; Neither true, neither not true; A little bit true; True; Totally true

Q2. Imagine a woman of your age who sends sexy photos to a match on a dating app, like Tinder. We would like to know which characteristics do you think are indicative for this woman. A woman who sends sexy photos through a dating app like Tinder is ... 1) attractive;

2) interesting; 3) desired [question displayed for women]

A: Totally not true; Not true; A little bit not true; Neither true, neither not true; A little bit true; True; Totally true

\section{Measure of Willingness to Sext}


Q1. Imagine that you meet someone on a dating app like Tinder with whom you exchange flirtatious messages; This person is highly sexually attractive. How likely is it that you would send the following photos of yourself to this Tinder match? 1) photos of yourself in a sexy pose but without naked body parts; 2) photos of yourself in underwear or swimwear; 3) nude photos.

A: highly unlikely; unlikely; a bit unlikely; neither likely, neither unlikely; a bit likely; highly likely

\section{Measures for Socio-Demographics}

Q1. [for gender] What is your gender?

A: Woman; Man

Q2. [for age] How old are you in years? (Please write a number)

Q3. [for sexual orientation] Are you attracted to boys or girls?

A: only to boys; mainly to boys, but also to girls; equally to boys and girls; mainly to girls, but also to boys; only to girls; I don't want to indicate the answer

Q4. [for relationship status] Do you currently have a committed relationship, or a romantic, serious relationship with someone?

A: Yes, I have a committed relationship, but we did not met each other through a dating app or the internet; Yes, I have a committed relationship, and we have met each other through a dating app or the internet; No, I don't have a committed relationship 


\section{REFERENCES}

Ajzen, I. (2002, September). Constructing a TpB questionnaire: Conceptual and methodological considerations. Retrieved from https://pdfs.semanticscholar.org/0574/b20bd58130dd5a961f1a2db10fd1fcbae95d.pdf.

Albury, K., \& Byron, P. (2014). Queering sexting and sexualisation. Media International Australia, 153, 138-147. doi:10.1177/1329878X1415300116

Albury, K., \& Byron, P. (2016). Safe on my phone? Same-sex attracted young people's negotiations of intimacy, visibility, and risk on digital hook-up apps. Social Media + Society, 2, 1-10. doi:10.1177/2056305116672887

Anderson, T. L. (2005). Relationships among internet attitudes, internet use, romantic beliefs, and perceptions of online romantic relationships. Cyberpsychology \& Behavior, 8 , 521-531. doi:10.1089/cpb.2005.8.521

Armenta, B. E., Hautala, D. S., \& Whitbeck, L. B. (2015). The utility of the Prototype/Willingness Model in predicting alcohol use among North American indigenous adolescents. Developmental Psychology, 51, 697-705. doi:10.1037/a0038978

Arnett, J. J. (2000). Emerging adulthood: A theory of development from the late teens through the early twenties. American Psychologist, 55, 469-480. doi:10.1037/0003-066X.55.5.469

Baumgartner, S. E., Sumter, S. R., Peter, J., \& Valkenburg, P. M. (2015). Sexual selfpresentation on social network sites: Who does it and how is it perceived? Computers in Human Behavior, 50, 91-100. doi:10.1016/j.chb.2015.03.061

Baumgartner, S. E., Sumter, S. R., Peter, J., Valkenburg, P. M., \& Livingstone, S. (2014). Does country context matter? Investigating the predictors of teen sexting across Europe. Computers In Human Behavior, 34, 157-164. doi:10.1016/j.chb.2014.01.041 
Baumgartner, S. E., Valkenburg, P. M., \& Peter, J. (2010). Unwanted online sexual solicitation and risky sexual online behavior across the lifespan. Journal of Applied Developmental Psychology, 31, 439-447. doi:10.1016/j.appdev.2010.07.005

Benotsch, E. G., Snipes, D. J., Martin, A. M., \& Bull, S. S. (2013). Sexting, substance use, and sexual risk behavior in young adults. Journal of Adolescent Health, 52, 307-313. doi:10.1016/j.jadohealth.2012.06.011

Berkowitz, A. D. (2005). An overview of the social norms approach. In L. C. Lederman, \& L. P. Stewart (Ed.), Challenging the Culture of College Drinking: A Socially situated Health Communication Campaign (pp. 193-214). Cresskill, NJ: Hampton Press.

Blanton, H., VandenEijnden, R. J., Buunk, B. P., Gibbons, F. X., Gerrard, M., \& Bakker, A. (2001). Accentuate the negative: Social images in the prediction and promotion of condom use. Journal of Applied Social Psychology, 31, 274-295.

doi:10.1111/j.15591816.2001.tb00197.x

Boot, I., Peter, J., \& van Oosten, J. M. F. (2016). Liking a sexual character affects willingness to have casual sex: The moderating role of relationship status and status satisfaction. Journal of Media Psychology, Theories, Methods, and Applications, 28, 51-64. doi:10.1027/1864-1105/a000145

Bohner, G., \& Dickel, N. (2011). Attitudes and attitude change. Annual Review of Psychology, 62, 391-417. doi:10.1146/annurev.psych.121208.131609

Borsari, B., \& Carey, K. B. (2001). Peer influences on college drinking: A review of the research. Journal of Substance Use, 13, 391-424. doi:10.1016/S0899-3289(01)00098-0

Bosveld, W., Koomen, W., van Der Pligt, J., \& Plaisier, J. W. (1995). Differential construal as an explanation for false consensus and false uniqueness effects. Journal of Experimental Social Psychology, 31, 518-532. doi:10.1006/jesp.1995.1023 
Burkett, M. (2015). Sex(t) talk: A qualitative analysis of young adults' negotiations of the pleasures and perils of sexting. Sexuality \& Culture, 16, 835-863. doi:10.1007/s12119-015-9295-0

Byrne, B. M. (2010). Structural equation modeling with AMOS: Basic concepts, applications, and programming (Second ed.). London: Routledge.

Claxton, S. E., \& van Dulmen, M. H. M. (2013). Casual sexual relationships and experiences in emerging adulthood. Emerging Adulthood, 1, 138-150. doi: $10.1177 / 2167696813487181$

Crozier, A. J., \& Taylor, K. L. (2019). An exploratory study examining the interactive effect of descriptive norm and image appeal messages on adults' physical activity intentions: A test of deviation regulation theory. Journal of Health Communication, 24, 195-202. doi:10.1080/10810730.2019.1593553

Dake, J. A., Price, J. H., Maziarz, L., \& Ward, B. (2012). Prevalence and correlates of sexting behavior in adolescents. American Journal of Sexuality Education, 7, 1-15. doi:10.1080/15546128.2012.650959

Davies, E. L., Martin, J., \& Foxcroft, D. R. (2015). Development and acceptability of a coproduced online intervention to prevent alcohol misuse in adolescents: A think aloud study. JMIR Human Factors, 2, 1-13. doi:10.2196/humanfactors.4452

Donn, J. E., \& Sherman, R. C. (2002). Attitudes and practices regarding the formation of romantic relationships on the internet. Cyberpsychology \& Behavior, 5, 107-123. doi:10.1089/109493102753770499

Döring, N. (2014). Consensual sexting among adolescents: Risk prevention through abstinence education or safer sexting? Cyberpsychology: Journal of Psychosocial Research on Cyberspace, 8. doi:10.5817/CP2014-1-9

Fincham, F. D., \& Cui, M. (2011). Romantic relationships in emerging adulthood. 
Cambridge: Cambidge University Press.

Finkel, E. J., Eastwick, P. W., Karney, B. R., Reis, H. T., Sprecher, S. (2012). Online dating: A critical analysis from the perspective of psychological science. Psychological Science in the Public Interest, 13, 3-66. doi:10.1177/1529100612436522

Gardner, D.G., Cummings, L. L., Dunham, R. B., \& Pierce, J. L. (1998). Single-item versus multiple-item measurement scales: An empirical comparison. Educational and Psychological Measurement, 58, 898-915. doi:10.1177/0013164498058006003

Gerrard, M., Gibbons, F. X., Stock, M. L., Lune, L. S. V., \& Cleveland, M. J. (2005). Images of smokers and willingness to smoke among African American pre-adolescents: An application of the Prototype/Willingness Model of adolescent health risk behavior to smoking initiation. Journal of Pediatric Psychology, 30, 305-318. doi:10.1093/jpepsy/jsi026

Gibbons, F. X., \& Gerrard, M. (1995). Predicting young adults' health risk behavior. Journal of Personality and Social Psychology, 69, 505-517. doi:10.1037/0022-3514.69.3.505

Gibbons, F. X., Gerrard, M., Blanton, H., \& Russell, D. W. (1998). Reasoned action and social reaction: Willingness and intention as independent predictors of health risk. Journal of Personality and Social Psychology, 74, 1164-1180. doi:10.1037/0022-3514.74.5.1164

Giordano, P., Longmore, M., \& Manning, W. (2006). Gender and the meanings of adolescent romantic relationships: A focus on boys. American Sociological Review, 71, 260-287. doi:10.1177/000312240607100205

Glasman, L. R., \& Albarracín, D. (2006). Forming attitudes that predict future behavior: A meta-analysis of the attitude-behavior relation. Psychological Bulletin, 132, 778-822. doi:10.1037/0033-2909.132.5.778

Gliem, J. A., \& Gliem; R. R. (2003, October). Calculating, interpreting, and reporting 
cronbach's alpha reliability coefficient for Likert-type scales. Paper presented at the Midwest Research-to-Practice Conference in Adult, Continuing, and Community Education, The Ohio State University, Columbus, $\mathrm{OH}$.

Griffin, M., Canevello, A., \& Mcanulty, R. D. (2018). Motives and concerns associated with geosocial networking app usage: An exploratory study among heterosexual college students in the United States. Cyberpsychology, Behavior, and Social Networking, 21, 268-275. doi:10.1089/cyber.2017.0309

Hallam, L., Walrave, W., \& De Backer, C. J. S. (2018). Information disclosure, drust and health risks in online dating. In M. Walrave, J. Van Ouytsel, K. Ponnet, \& J. R. Temple (Ed.), Sexting: Motives and risk in online sexual self-presentation (pp. 19-38). Nottingham, UK: Palgrave.

Helsper, E. J., \& Whitty, M. T. (2010). Netiquette within married couples: Agreement about acceptable online behavior and surveillance between partners. Computers in Human Behavior, 26, 916-926. doi:10.1016/j.chb.2010.02.006

Hukkelberg, S. S., \& Dykstra, J. L. (2009). Using the Prototype/Willingness Model to predict smoking behaviour among Norwegian adolescents. Addictive Behaviors, 34, 270-276. doi:10.1016/j.addbeh.2008.10.024

Kenny, P., \& Hastings, G. (2011). Understanding social norms: Upstream and downstream applications for social marketers. In G. Hastings, K. Angus, \& C. Bryant (Ed.), The Sage handbook of social marketing (pp. 61-79). London: Sage.

Kinsey, A. C., Pomeroy, W. B, \& Martin, C. E. (1948). Sexual behavior in the human male. Philadelphia: W. B. Saunders.

Klettke, B., Hallford, D. J., \& Mellor, D. J. (2014). Sexting prevalence and correlates: A systematic literature review. Clinical Psychology Review, 34, 44-53. doi:10.1016/j.cpr.2013.10.007 
Kline, R. B. (2011). Principles and practice of structural equation modeling. New York: The Guilford Press.

Litt, D. M., \& Lewis, M. A. (2016). Examining a social reaction model in the prediction of adolescent alcohol use. Addictive Behaviors, 60, 160-164. doi:10.1016/j.addbeh.2016.04.009

Lutz, C., \& Ranzini, G. (2017). Where dating meets data: Investigating social and institutional privacy concerns on Tinder. Social Media + Society, 3, 1-12. doi:10.1177/2056305117697735

Mitchell, K. J., Finkelhor, D., \& Jones, L. M., \& Wolak, J. (2012). Prevalence and characteristics of youth sexting: A national study. Pediatrics, 129, 13-20. doi:10.1542/peds.2011-1730

Morgan, E. M. (2013). Contemporary issues in sexual orientation and identity development in emerging adulthood. Emerging Adulthood, 1, 52-66. doi:10.1177/2167696812469187

Mori, C., Cooke, J. E., Temple, J. R., Ly, A., Lu, Y., Anderson, N., et al. (2020). The prevalence of sexting behaviors among emerging adults:A meta-analysis. Archives of Sexual Behavior. doi:10.1007/s10508-020-01656-4

Netting, N .S., \& Burnett, M. L. (2004). Twenty years of student sexual behavior: Subcultural adaptions to a changing health environment. Adolescence, 39, 19-38. Retrieved from https://search.proquest.com/

Peter, J., \& Valkenburg, P. M. (2011). The use of sexually explicit internet material and its antecedents: A longitudinal comparison of adolescents and adults. Archives of Sexual Behavior, 40, 1015-1025. doi:10.1007/s10508-010-9644-х

Petersen, J. L., \& Hyde, J .S. (2010). A meta-analytic review of research on gender differences in sexuality: 1993 to 2007. Psychological Bulletin, 36, 21-38. doi:10.1037/a0017504 
Pool, G. J., \& Schwegler, A. F. (2007). Differentiating among motives for norm conformity. Basic and Applied Social Psychology, 29, 47-60. doi:10.1080/01973530701330983

Poulsen, F. O., Holman, T. B., Busby, D. M., Carroll, J. S. (2013). Physical attraction, attachment styles, and dating development. Journal of Social and Personal Relationships, 30, 301-319. doi:10.1177/0265407512456673

Ranzini, G., \& Lutz, C. (2017). Love at first swipe? Explaining Tinder self-presentation and motives. Mobile Media \& Communication, 5, 80-101. doi:10.1177/2050157916664559

Sawyer, A. N., Smith, E. R., \& Benotsch, E. G. (2018). Dating application use and sexual risk behavior among young adults. Sexuality Research and Social Policy, 15, 183-191.

Smith, A., \& Anderson, M. (2016). 5 facts about online dating. Washington, DC: Pew Research Center.

Stephenson, K. R., \& Sullivan, K. T. (2009). Social norms and general sexual satisfaction: The cost of misperceived descriptive norms. Canadian Journal of Human Sexuality, 18, 89-105. Retrieved from http://www.researchgate.net

Sumter, S. R., \& Vandenbosch, L. (2018). Dating gone mobile: Demographic and personality-based correlates of using smartphone-based dating applications among emerging adults. New Media \& Society, 21, 655-673. doi:10.1177/1461444818804773

Sumter, S. R., Vandenbosch, L., \& Ligtenberg, L. (2017). Love me Tinder: Untangling emerging adults' motivations for using the dating application Tinder. Telematics and Informatics, 34, 67-78. doi:10.1016/j.tele.2016.04.009

van Lettow, B., de Vries, H., Burdorf, A., Boon, B., \& Van Empelen, P. (2015). Drinker prototype alteration and cue reminders as strategies in a tailored web-based intervention reducing adults' alcohol consumption: Randomized controlled trial. Journal of Medical Internet Research, 17, 1-35. doi:10.2196/jmir.3551 
van Oosten, J. M. F., Peter, J., \& Boot, I. (2015). Exploring associations between exposure to sexy online self-presentations and adolescents' sexual attitudes and behavior. Journal of Youth and Adolescence, 44, 1078-1091. doi:10.1007/s10964-014-0194-8

van Oosten, J. M. F., Peter, J., \& Vandenbosch, L. (2017). Adolescents's sexual media use and willingness to engage in casual sex: Differential relations and underlying processes. Human Communication Research, 43, 127-147. doi:10.1111/hcre.12098

van Oosten, J. M. F., \& Vandenbosch, L. (2017). Sexy online self-presentation on social network sites and the willingness to engage in sexting: A comparison of gender and age. Journal of Adolescence, 54, 42-50. doi:10.1016/j.adolescence.2016.11.006

Van Ouytsel, J., Walrave, M., \& Ponnet, K. (2018). Adolescent sexting research: The challenges ahead. JAMA Pediatrics, 172, 405-406. doi:10.1001/jamapediatrics.2018.0013

Van Ouytsel, J., Walrave, M., Ponnet, K., \& Heirman, W. (2015). The association between adolescent sexting, psychosocial difficulties, and risk behavior: Integrative review. Journal of School Nursing, 31, 54-69. doi:10.1177/1059840514541964

Vandenbosch, L. (2015). Antecedents of adolescents' exposure to different types of sexually explicit Internet material: A longitudinal study. Computers in Human Behavior, 50, 439-448. doi:10.1016/j.chb.2015.04.032

Walrave, M., Ponnet, K., Van Ouytsel, J., Van Gool, E., Heirman, W., \& Verbeek, A. (2015). Whether or not to engage in sexting: Explaining adolescent sexting behaviour by applying the prototype willingness model. Telematics and Informatics, 32, 796-808. doi:10.1016/j.tele.2015.03.008

Wanous, J. P., Reichers, A. E., \& Hudy, M. J. (1997). Overall job satisfaction: How good are single-item measures? Journal of Applied Psychology, 82, 247-252. doi:10.1037/0021-9010.82.2.247 
Ward, J. (2016). What are you doing on Tinder? Impression management on a matchmaking mobile app. Information, Communication \& Society, 20, 1644-1659. doi:10.1080/1369118X.2016.1252412

Wiederhold, B. K. (2015). Does sexting improve adult sexual relationships? Cyberpsychology, Behavior, and Social Networking, 18, 627-627. doi:10.1089/cyber.2015.29014.bkw

Willoughby, B. J., \& Carroll, J. S. (2010). Sexual experience and couple formation attitudes among emerging adults. Journal of Adult Development, 17, 1-11. doi:10.1007/s10804-009-9073-Z 


\section{List of Figures}

Figure 1. Hypothesized model.

Figure 2. Structural equation model for the hypothesized relations.

\section{List of Tables}

Table 1. Descriptive statistics 


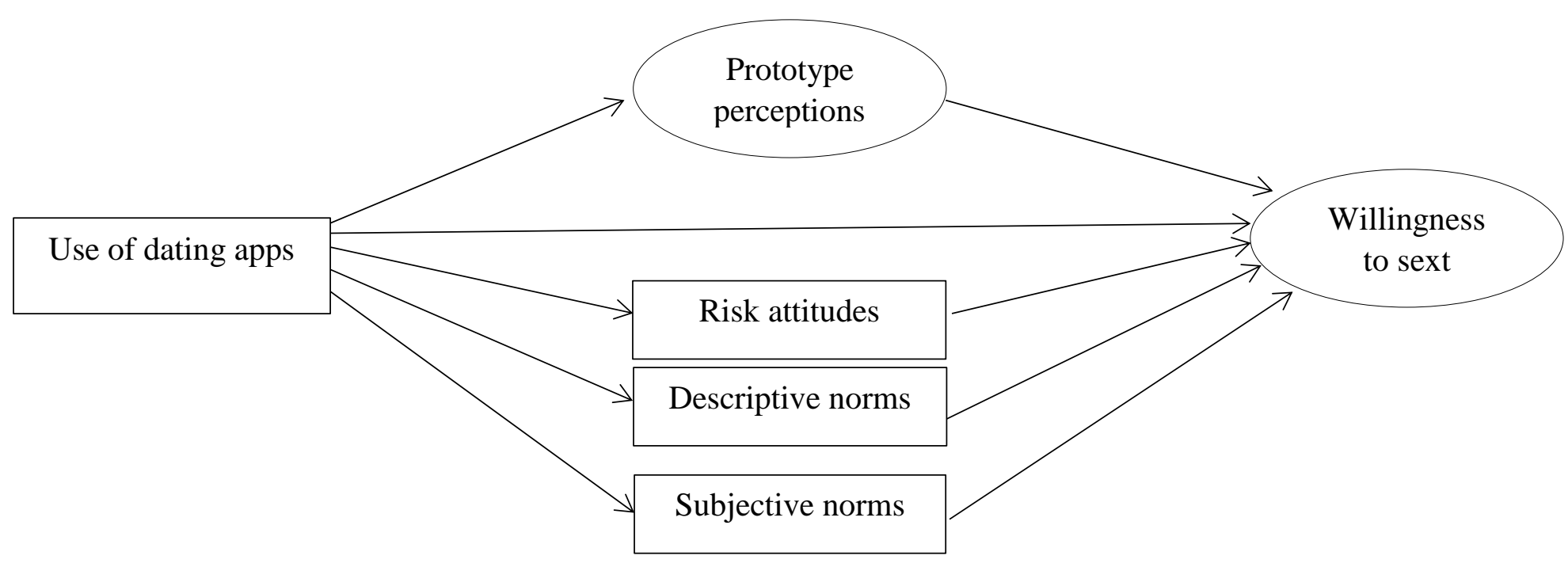

Figure 1. Hypothesized model.

Note. Rectangles represent observed variables, ovals represent latent constructs. The latent variable "prototype perceptions" is based on 3 items.

The latent variable "willingness to sext" is based on 3 items. 


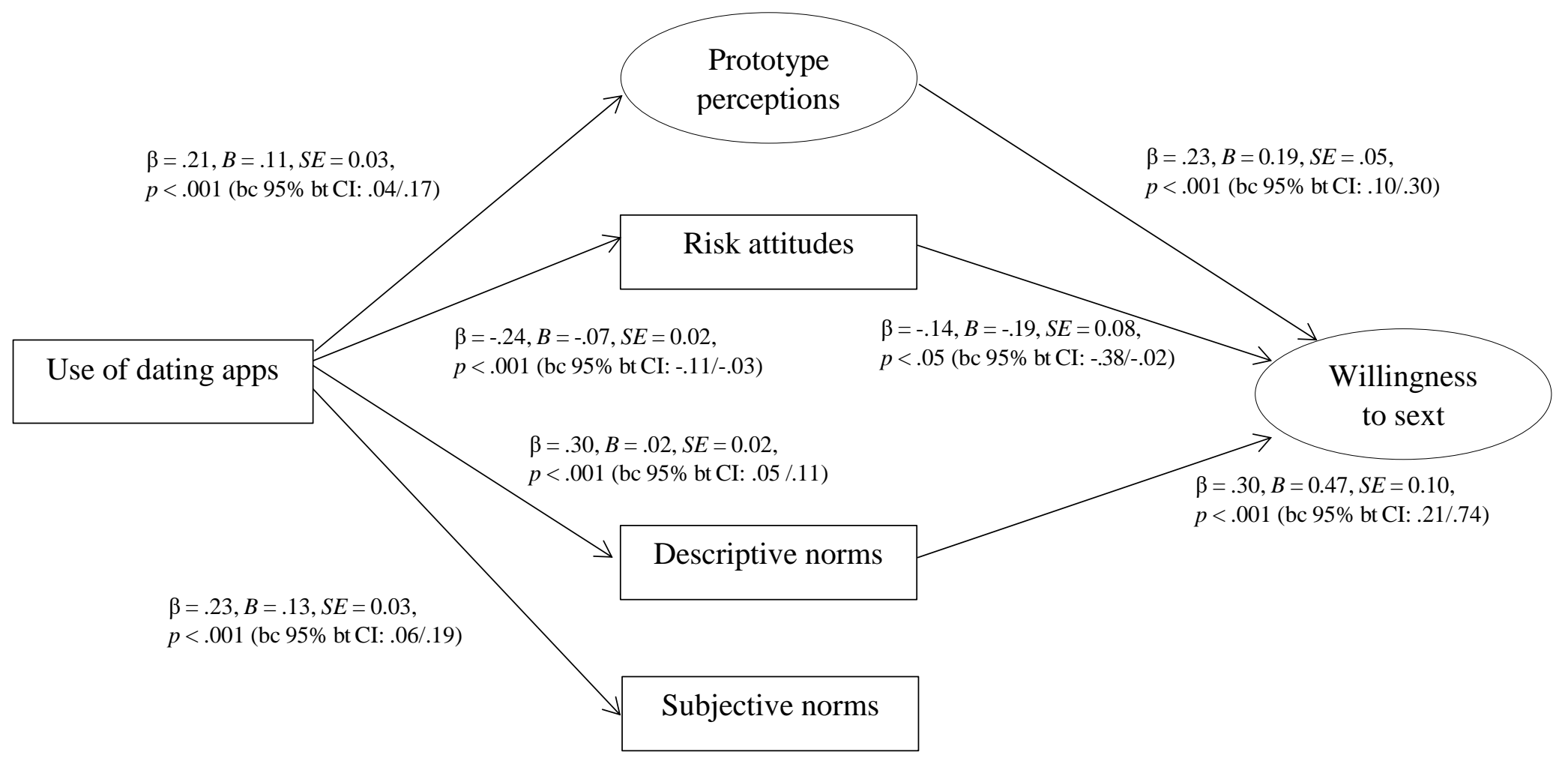

Figure 2. Structural equation model for the hypothesized relations.

Note. Rectangles represent observed variables, ovals represent latent constructs. The latent variable "prototype perceptions" is based on 3 items.

The latent variable "willingness to sext" is based on 3 items. All displayed paths were significant in the tested model (at $p<.05)$. For clarity,

error terms, covariance and measurements are not shown. 
Table 1. Descriptive statistics

\begin{tabular}{|c|c|c|c|c|c|c|c|c|c|c|c|}
\hline & $M$ & $S D$ & & & & & Zero & der corl & ons & & \\
\hline & & & 1 & 2 & 3 & 4 & 5 & 6 & 7 & 8 & 9 \\
\hline 1. Dating app use & 2.92 & 3.04 & - & $.31^{* *}$ & $.23^{* *}$ & $-.25^{* *}$ & $.22^{* *}$ & $.22^{* *}$ & .05 & $.19^{* *}$ & .01 \\
\hline 2. Descriptive norms & 1.51 & 0.79 & & - & $.40^{* *}$ & $-.31^{* *}$ & $.13^{*}$ & $.40^{* *}$ & .01 & $.13^{*}$ & .01 \\
\hline 3. Subjective norms & 3.06 & 1.65 & & & - & $-.34^{* *}$ & $.33^{* *}$ & $.35^{* *}$ & .09 & .00 & -.00 \\
\hline 4. Risk attitudes & 3.79 & 0.91 & & & & - & $-.23^{* *}$ & $-.32^{* *}$ & -.11 & -.10 & -.08 \\
\hline 5. Prototype perceptions & 3.03 & 1.58 & & & & & - & $.32^{* *}$ & .09 & .11 & -.00 \\
\hline 6. Willingness to sext & 2.14 & 1.27 & & & & & & - & .12 & $.23^{* *}$ & .04 \\
\hline 7. Age & 24.32 & 3.46 & & & & & & & - & -.02 & $.23^{* *}$ \\
\hline 8. Sexual orientation ${ }^{\mathrm{a}}$ & .16 & .37 & & & & & & & & - & -.05 \\
\hline 9. Relationship status ${ }^{\mathrm{b}}$ & .62 & .48 & & & & & & . & & & - \\
\hline
\end{tabular}

Note. ${ }^{* *} p<.01 ; * p<.05$. Dichotomous variables are coded as follows; ${ }^{\text {a }}$ sexual orientation: exclusively heterosexual $=0$, not exclusively

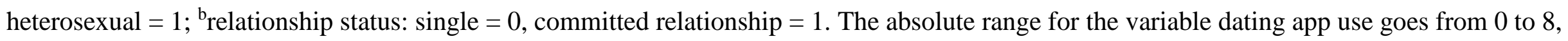

for the variables descriptive norms and risk attitudes from 1 to 5 and for the variables subjective norms, prototype perceptions and sexting

willingness from 1 to 7 . 